differential diagnosis of patients with APL from patients with HLA-DR-negative non-APL.

Keywords: AML-M3, CD9, Flow cytometry, HLA-DR-negative AML

Anahtar Kelimeler: AML-M3, CD9, Akım sitometri, HLA-DR negative AML

\section{Authorship Contributions}

Design: E.S.S., M.M., M.o.M., Data collection: E.S.S., Analysis: M.M., Writing: M.o.M.

Conflict of Interest: The authors declare no conflict of interest.

\section{References}

1. Touzet L, Dumezy F, Roumier C, Berthon C, Bories C, Quesnel B, Preudhomme C, Boyer T. CD9 in acute myeloid leukemia: prognostic role and usefulness to target leukemic stem cells. Cancer Med 2019;8:1279-1288.
2. Allahbakhshian M, Shahabi Satlsar E, Mohseni A, Mosleh M, Mehrpouri M, Agaeipour M, Mohammadi MH, Gholampour R, Jadali F. Use of four-color flow cytometric assay for discrimination of hematogone from lymphoblast: critical issue for MRD assessment in B-ALL patients. Iran J Ped Hematol Oncol 2020;10:17-27.

3. Yamazaki $\mathrm{H}, \mathrm{Xu} \mathrm{CW}$, Naito $\mathrm{M}$, Nishida $\mathrm{H}, \mathrm{Okamoto} \mathrm{T}$, Ghani Fl, Iwata $\mathrm{S}$, Inukai T, Sugita K, Morimoto C. Regulation of cancer stem cell properties by CD9 in human B-acute lymphoblastic leukemia. Biochem Biophys Res Commun 2011;409:14-21.

4. Adams J, Nassiri M. Acute promyelocytic leukemia: a review and discussion of variant translocations. Arch Pathol Lab Med 2014;139:1308-1313.

5. Wetzler M, McElwain BK, Stewart CC, Blumenson L, Mortazavi A, Ford LA, Slack JL, Barcos M, Ferrone S, Baer MR. HLA-DR antigen-negative acute myeloid leukemia. Leukemia 2003;17:707-715.

6. Mosleh M, Mehrpouri M, Ghaffari S, Saei Z, Agaeipoor M, Jadali F, Satlsar ES, Gholampour R. Report of a new six-panel flow cytometry marker for early differential diagnosis of APL from HLADR negative non-APL leukemia. Scand J Clin Lab Invest 2020;80:87-92.

7. Akhtar K, Ahmad S, Shervani RK. Acute promyelocytic leukemia, hypogranular variant: a rare presentation. Clin Pract 2011;1:e11.

\title{
Comment: In Response to "CD9 Is a Very Helpful Marker for Discriminating AML-M3 from HLA-DR-Negative Non-M3 AML"
}

\section{Yorum: "CD9 AML-M3'ü HLA-DR Negatif M3 Dışı AML'den Ayırt Etmede Çok Faydalı Bir Belirteçtir}

(D) Smeeta Gajendra

Laboratory Oncology Unit, Dr. B.R.A. IRCH, AIIMS, New Delhi, India

\section{To the Editor,}

I read the letter "CD9 Is a Very Helpful Marker for Discriminating AML-M3 from HLA-DR-Negative Non-M3 AML" by Satlsar et al. [1], published in this journal. The manuscript is well written with description of a very informative topic of expression pattern of CD9 in acute promyelocytic leukemia (APL). There is bright homogeneous expression of CD9 in APL, whereas the expression is dimmer and heterogeneous in non-APL cases. CD9 is a tetraspanin molecule that is expressed on a wide variety of hematopoietic cells as precursor B cell, megakaryocytes, and certain acute myeloid leukemias. CD9 is associated with poor prognosis in ALL and good prognosis in AML cases. CD9 can be used as a biomarker and can be considered as therapeutic target. APL has distinct morphologic, biologic, and clinical features. The diagnosis is predominantly based on morphology which is characterized by presence of abnormal promyelocytes with bilobed nuclei and frequent Auer rods and a cytogenetic/molecular hallmark of $\mathrm{t}(15 ; 17)(\mathrm{q} 22 ; \mathrm{q} 21) \quad P M L-R A R A$. Multiparameter flow cytometry evolved as a rapid diagnostic tool along with morphology for early detection and immediate starting of therapy to avoid life threatening complications. On flow cytometry, these abnormal promyelocytes have a teardrop pattern with high SCC in CD45SSC plots due to prominent granulations which mimic the position of granulocytes but lack CD15, CD16, and CD11c, which 
would be present on neutrophils. These are predominantly CD34-HLA DR negative with myeloperoxidase, CD13, CD33, and CD117 positive. Aberrant expression of CD2 and CD56 is commonly seen. They characteristically lack expression of the $\beta 2$-integrins CD11a, CD11b, CD11c, and CD18 in 100\% cases $[2,3]$. However, CD11a and CD18 are absent in 39\% and 45\% of non-APL cases, respectively [4]. Many studies have shown that the absence of CD34 and HLA-DR is not specific for APL and about 50\% of HLA-DR negative cases include other AML subtypes [5]. HLA-DR and CD34 negativity is a distinctive feature of "AML-cuplike" with FLT3-ITD [6] and in AML-M1 and AML-M2 subtypes with NPM1 mutation [7]. CD9 is expressed in around 40\% cases of AML [8]. Liu et al. [9] showed a significant expression of CD9 in AML with NPM1 mutation. Thus, as a single marker presence of CD9 or absence of HLA-DR, CD18, or CD11a loses specificity in diagnosis of APL. Therefore, a combination of cMPO, CD34, HLADR, CD117, CD33, CD15, CD11c, CD64, CD9, and CD18 can diagnose APL with high specificity and sensitivity by excluding other hypergranular AML as few cases of NPM1-positive AML mimicking APL on morphology and also in cases showing CD34 and HLA-DR negativity on flow cytometry, that can pose a diagnostic dilemma. However, definitive diagnosis of APL requires cytogenetic or molecular study.

Keywords: Acute promyelocytic leukemia, Flow cytometry, CD9, CD18

Anahtar Sözcükler: Akut promiyelositik lösemi, Akış sitometrisi, CD9, CD18

Financial Disclosure: The authors declared that this study received no financial support.

\section{References}

1. Satlsar ES, Mosleh M, Mehrpouri M. CD9 is a very helpful marker for discriminating AML-M3 from HLA-DR negative non-M3 AML. Turk J Hematol 2020;37:287-289.

2. Dong HY, Kung JX, Bhardwaj V, McGill J. Flow cytometry rapidly identifies all acute promyelocytic leukemias with high specificity independent of underlying cytogenetic abnormalities. Am J Clin Pathol 2011;1:76-84.

3. Bain BJ, Béné MC. Morphological and immunophenotypic clues to the WHO categories of acute myeloid leukaemia. Acta Haematol 2019;141:232-244.

4. Zhou Y, Jorgensen JL, Wang SA, et al. Usefulness of CD11a and CD18 in flow cytometric immunophenotypic analysis for diagnosis of acute promyelocytic leukemia. Am J Clin Pathol. 2012;138:744-750.

5. Zhou Y, Jorgensen JL, Wang SA, Ravandi F, Cortes J, Kantarjian HM, Medeiros $\sqcup$, Konoplev S. Usefulness of CD11a and CD18 in flow cytometric immunophenotypic analysis for diagnosis of acute promyelocytic leukemia. Am J Clin Pathol 2012;138:744-750.

6. Kussick SJ, Stirewalt DL, Yi HS, Sheets KM, Pogosova-Agadjanyan E, Braswell S, Norwood TH, Radich JP, Wood BL. A distinctive nuclear morphology in acute myeloid leukemia is strongly associated with loss of HLA-DR expression and FLT3 internal tandem duplication. Leukemia 2004;18:15911598.

7. Syampurnawati $M$, Tatsumi $E$, Ardianto B, Takenokuchi M, Nakamachi $Y$, Kawano S, Kumagai S, Saigo K, Matsui T, Takahashi T, Nagai K, Nishio H, Yabe $H$, Kondo $S$, Hayashi Y. DR negativity is a distinctive feature of M1/M2 AML cases with NPM1 mutation. Leuk Res 2008;32:1141-1143.

8. Touzet L, Dumezy F, Roumier C, Berthon C, Bories C, Quesnel B, Preudhomme C, Boyer T. CD9 in acute myeloid leukemia: Prognostic role and usefulness to target leukemic stem cells. Cancer Med 2019;8:1279-1288.

9. Liu YR, Zhu HH, Ruan GR, Qin Y-Z, Shi H-X, Lai Y-Y, Chang Y, Wang Y-Z, Lu D, Hao L, Li J-L, Li L-D, Jiang B, Huang X-J. NPM1-mutated acute myeloid leukemia of monocytic or myeloid origin exhibit distinct immunophenotypes. Leuk Res 2013;37:737-741.

In reply to: Comment: In response to "CD9 Is a Very Helpful Marker for Discriminating AML-M3 from HLA-DR Negative Non-M3-AML"

\section{To the Editor,}

We are proud that our research has received attention. This research is a part of continuous research for precise flow cytometry detection of acute promyelocytic leukemia [1]. The use of myeloid markers such as CD13, CD33, CD64, CD117, CD34, HLA-DR, and CD11b is essential for diagnosis of APL, as we mentioned in the last paragraph. In clinical practice differential diagnosis of HLA-DR-negative AML from APL is very crucial and using different markers can be very helpful in these cases. Our aim is to introduce CD9 further to increase the specificity and sensitivity of flow cytometry, which can be used with other markers as complementary marker.

Best Regards,

Esmaeil Shahabi Satlsar, Mohammad Mosleh, Mahdieh Mehrpouri

\section{References}

1. Mosleh M, Mehrpouri M, Ghaffari S, Saei Z, Agaeipoor M, Jadali F, Satlsar ES, Gholampour R. Report of new six-panel flow cytometry for early differential diagnosis of APL from HLA-DR negative Non-APL leukemia. Scand J Clin Lab Invest 2020;80:87-92. 